\title{
Correction to: Sheep exploitation and husbandry in first farming societies: from production to consumption in Central Pyrenees in the Early Neolithic
}

\author{
Alejandro Sierra $^{1}$ (D) - Stéphanie Bréhard ${ }^{2} \cdot$ Lourdes Montes $^{1} \cdot$ Pilar Utrilla $^{1} \cdot$ María Saña $^{3}$
}

Published online: 30 August 2019

(C) Springer-Verlag GmbH Germany, part of Springer Nature 2019

\section{Correction to: Archaeological and Anthropological Sciences} https://doi.org/10.1007/s12520-019-00907-3

The original version of this article, unfortunately, contained errors. Fig. 5 found out to be identical with Fig. 3. Given in this article is the correct Fig. 5.

The original article has been corrected.

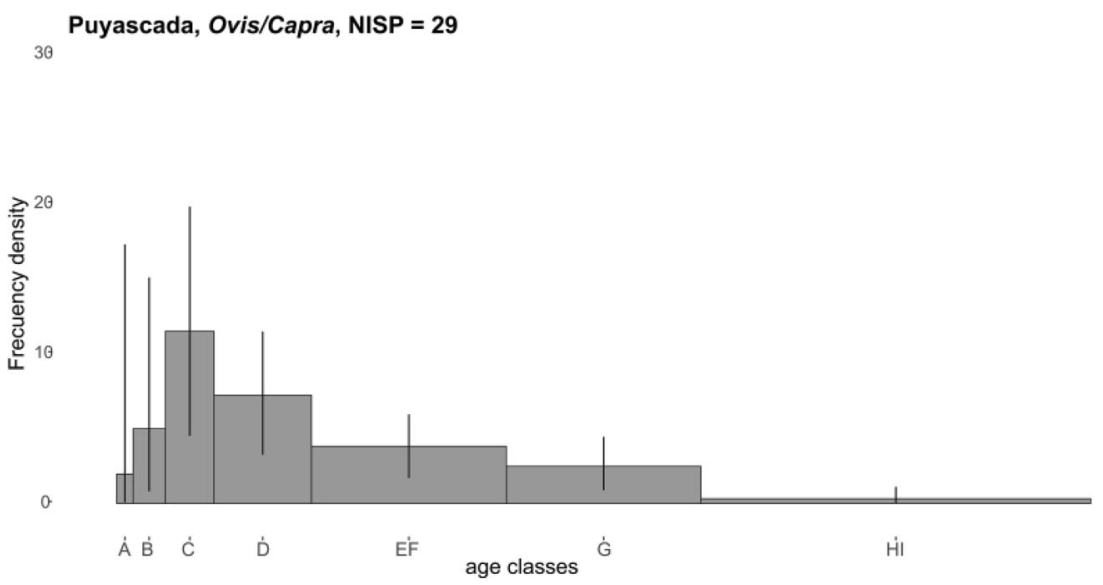

Publisher's note Springer Nature remains neutral with regard to jurisdictional claims in published maps and institutional affiliations.

The online version of the original article can be found at https://doi.org/ 10.1007/s12520-019-00907-3

Alejandro Sierra

asierras@unizar.es

Stéphanie Bréhard

brehard@mnhn.fr

Lourdes Montes

lmontes@unizar.es

Pilar Utrilla

utrilla@unizar.es
María Saña

maria.sana@uab.cat

1 Área de Prehistoria - Instituto de Investigación en Ciencias Ambientales (IUCA), Universidad de Zaragoza, Zaragoza, Spain

2 Archéozoologie, Archéobotanique: Sociétés, Pratiques et Environnement (UMR7209), Muséumnational d'Histoire naturelle CNRS, CP56, 55 rue Buffon, F-75005 Paris, France

3 Departament de Prehistòria, Universitat Autònoma de Barcelona, Barcelona, Spain 